\title{
Bibliotecas infernais
}

\author{
Hellish Library \\ Tiago Guilherme PINHEIRO* \\ Universidade de São Paulo (USP)
}

\begin{abstract}
RESUMO: Este artigo elabora, a partir do conto "La biblioteca de Babel", a descrição de um mecanismo que propomos chamar "biblioteca infernal" cujo funcionamento é constitutivo de diversos textos do escritor argentino Jorge Luis Borges. Por meio desse conceito, gostaríamos de exibir a problemática do conflito entre a enunciação do texto literário e o espaço que ele ocupa nas estruturas - concreta e simbólicas - de nossas bibliotecas, entre a calculabilidade estática de um arquivo e a necessidade de evocar a memória com força escritural. Com isso, esperamos apontar a importância desse maquinário na produção latino-americana mais recente, tais como as de Roberto Bolaño e Rodrigo Rey Rosa, principalmente no que concerne a tensão entre o lugar da literatura e o dos espólios das ditaduras militares em tempos de governos democráticos.
\end{abstract}

PALAVRAS-CHAVE: Jorge Luis Borges. Literatura latino-americana. Literatura contemporânea. Biblioteca. Ditaduras militares latino-americanas.

\begin{abstract}
This article elaborates, from the short-story "La biblioteca de Babel" the description of a mechanism we intend to name as "hellish library", which has a constitutive role in several texts of the Argentine writer Jorge Luis Borges. Through this concept we'd like to show the problematique of the conflict between the enunciation of the literary text and the space it occupies in the structures - both concrete and symbolical - of our libraries, between static calculability of an archive and the need to evoke memory with writing force. Thus we intend to point the importance of this machinery in the most recent Latin-American literary production, in works such as the ones by Roberto Bolaño and Rodrigo Rey Rosa, mainly in what concerns the tension between literature's role and the heritage of military dictatorships in times of democratic governments.
\end{abstract}

KEYWORDS: Jorge Luis Borges. Latin American literature. Contemporary literature. Library. Latin American military dictatorships.

\section{Introdução}

Gostaria de examinar aqui algumas questões concernentes à obra do escritor argentino Jorge Luis Borges (1899-1986), buscando traçar, a partir da leitura de um dos seus contos mais famosos, "La biblioteca de Babel" do livro Ficciones (1944), a descrição de um dispositivo que proponho chamar de "bibliotecas infernais", mecanismo que se estabelece a partir de uma relação conflituosa e mesmo disruptiva entre o texto, suas potencialidades, e o lugar simbólico, histórico e material que surge a partir de um modelo institucional de organização e catalogação de livros próprio do ocidente. Espero com isso oferecer uma pequena contribuição para a compreensão não só de certas recorrências na obra de Borges, como também sugerir a importância que o problema toma em escritores

\footnotetext{
* Bacharel em Comunicação Social - Jornalismo pela PUC-PR e em Letras pela USP, doutorando e bolsista FAPESP pelo Departamento de Teoria Literária e Literatura Comparada da Faculdade de Filosofia, Letras e Ciências Humanas da Universidade de São Paulo (USP). São Paulo-SP. Email: tg_pinheiro@ yahoo.com.br.
} 
latino-americanos mais recentes, tanto na prosa como na poesia. Interessa, sobretudo, o modo como esse mecanismo é relido, ganhando novos avatares e usos na medida em que novas condições de enunciação surgem ao longo das décadas, como, por exemplo, aquela na qual se insere a obra do escritor chileno Roberto Bolaño (1953-2003) ou do guatemalteco Rodrigo Rey Rosa (1958), dois leitores bastante peculiares de Borges. Não à toa, seu nome é apresentado como uma referência explícita e constitutiva de livros como La literatura nazi en América (1996) e El material humano (2009), por exemplo.

Existe, dentro de um certo fabulário sobre Jorge Luis Borges e sua obra, a imagem que remete ao escritor ascético, obscuro, insistente em apologizar todo o tipo de cultura literária, afastado das questões políticas e sociais, e que tem por objetivo último usufruir um número sem fim de livros, por toda a eternidade. ${ }^{1}$ Um exemplo recente desse tipo de tratamento que busca conjugar essa versão da "vida e obra" do escritor argentino é o ensaio do Sérgio Miceli (2007), "Jorge Luis Borges: História social de um escritor nato", publicada na revista Novos Estudos Cebrap, no qual, ao propor desvelar os "artífices da legenda borgeana", dando-lhe uma explicação sociológica baseada nas relações pessoais do autor e no contexto cultural argentino das primeiras décadas do século XX, acaba reduplicando essa tal mitologia, investindo-a inclusive com traços de tragédia amorosa e de angústia edipiana. São frequentes as passagens em que certas especulações psicologizantes aparecem, como quando Miceli (2007, p. 161) fala da orfandade e do desejo por uma vida literária, herdado pelo pai, que, segundo o sociólogo, "se fez secundar pela 'opção' do celibato, pré-requisito que deve ter lhe parecido indispensável ao êxito de um projeto criativo de tal vulto". Ou ainda, na mesma página, observando as fotos de Jorge Guillermo adulto e do jovem Jorge Luis, vendo-lhes as semelhanças, chega à conclusão de haver um "empenho do filho em arremedar o jeitão másculo do pai, como se os laços de continuidade pudessem ser tirados a limpo pela impressionante parecença física".

Certamente, nos textos de Borges, o elogio ao livro não é raro, e quase chega a formar uma história pessoal de suas leituras. Porém, isso só parece ressaltar os textos igualmente frequentes - em que grandes instituições da cultura letrada, como por exemplo, a biblioteca e a enciclopédia, se transformam em dispositivos perversos que visam estabelecer um estado de imobilidade, de fechamento para outras dinâmicas possíveis de relação entre saberes e formas de vida. Inclusive, Borges aponta para os pontos de cumplicidade entre essas instituições e certas versões hegemônicas de valores e conceitos tais como memória, tempo, liberdade, universalidade, eternidade, etc. - que participaram na constituição da chamada "cultura ocidental moderna".

Para que possamos ser fiéis ao legado de Borges, aos potenciais não prescritos de seus textos, precisamos interrogar em sua obra sobre esse lugar ambíguo e conflituoso em que os livros do autor (e de outros) ocupam: a biblioteca.

\section{A lei da biblioteca}

Um ponto de partida privilegiado para esse questionamento é o conto "La biblioteca de Babel", escrito em 1941. Nesse texto amplamente conhecido, somos apresentados a uma biblioteca-universo (só há a Biblioteca) e a descrição de várias gerações de "bibliotecários", seus habitantes, que tentaram entendê-la ou meramente suportá-la. Com o

\footnotetext{
${ }^{1}$ Um exemplo desse tipo de imaginário pode ser encontrado no conto "Borges no inferno" do angolano José Eduardo Agualusa (2005), no qual o argentino, logo após a sua morte, encontra-se em meio a um vasto terreno cheio de bananeiras. Depois de certa especulação, ele chega à conclusão de que aquele paraíso é de outro: Deus o teria confundido com Gabriel García Márquez. E, então, consola-se triunfante imaginando o sofrimento que o colombiano deveria estar sentido passando a eternidade numa biblioteca escura.
} 
passar do tempo, o narrador nos conta, foi possível criar uma descrição arquitetural que dá forma a esse universo. O texto é muito cuidadoso nesse sentido, oferecendo reiteradamente a descrição dessa cosmologia pan-óptica que se repete indefinidamente:

\begin{abstract}
La distribución de las galerías es invariable. Veinte anaqueles, a cinco largos anaqueles por lado, cubren todos los lados menos dos; su altura, que es la de los pisos, excede apenas la de un bibliotecario normal. Una de las caras libres da a un angosto zaguán, que desemboca en otra galería, idéntica a la primera y a todas. A izquierda y a derecha del zaguán hay dos gabinetes minúsculos. Uno permite dormir de pie; otro, satisfacer las necesidades fecales. Por ahí pasa la escalera espiral, que se abisma y se eleva hacia lo remoto. En el zaguán hay un espejo, que fielmente duplica las apariencias.[...] La luz procede de unas frutas esféricas que llevan el nombre de lámparas. Hay dos en cada hexágono: transversales. La luz que emiten es insuficiente, incesante. (BORGES, 1974. p. 465$)^{2}$

A cada uno de los muros de cada hexágono corresponden cinco anaqueles; cada anaquel encierra treinta y dos libros de formato uniforme; cada libro es de cuatrocientas diez páginas; cada página, de cuarenta renglones, cada renglón, de unas ochenta letras de color negro. También hay letras en el dorso de cada libro; esas letras no indican o prefiguran lo que dirán las páginas. (BORGES, 1974, p. 466)
\end{abstract}

Do mesmo modo, o relato nos oferece a equação geral de todos os livros que povoam a Biblioteca, fórmula que garante a existência prévia de todas as possibilidades de escrita e fala, do passado e do futuro, do vivido e do não vivido, seja na língua que for inclusive as não inventadas ou esquecidas. "El número de símbolos ortográficos es veinticinco" (p.466), incluindo o ponto, a vírgula e o espaço em branco. A Biblioteca consiste no conjunto dos tomos que exaurem todas as possibilidades combinatórias desses sinais impressos, sem haver qualquer repetição de exemplares. Essa exaustão teria, entretanto, um largo excedente do ponto de vista comunicativo e pragmático, já que, a maior parte dos livros é simplesmente ilegível - é pura demonstração desse mesmo esgotamento. Como dispostos a encontrar uma contrapartida, seguindo os cálculos dessa mesma lógica, os bibliotecários anunciaram a existência prévia de todo e qualquer saber consistente e libertador - bastava encontrá-lo. Do mesmo modo que existe uma incontável exemplaridade da falta de sentido imposta por essa arbitrariedade - cujo contato diário e constante levou muitos ao suicídio ou a loucura -, haveria de existir um exemplar que concentrasse toda a infinidade de sentido, de saberes, que justificasse a existência de todos os outros: "Todos los hombres se sintieron señores de un tesoro intacto y secreto. No había problema personal o mundial cuya elocuente solución no existiera: en algún hexágono. El universo estaba justificado, el universo bruscamente usurpó las dimensiones ilimitadas de la esperanza" (p.468). Essa expectativa motivou largas buscas desesperadas dos habitantes dessa Biblioteca, cujos relatos das diversas incursões malfadadas, que muitas vezes lembram o tom das narrativas das Cruzadas, compõem boa parte do conto. Segue-se que toda a esperança dos bibliotecários, que também foi a do narrador, reside em encontrar "o livro dos livros", o "catálogo geral da biblioteca", o "Homem do Livro" equivalente a deus, o "livro circular" e outros símbolos messiânicos, variantes hiperbólicas dessa coleção infinita. Mesmo as especulações da existência de pequenas variações - uma sala carmesim ou uma série de livros com formatos menores e páginas ilustradas - já se dá como promessa, como promessa de uma promessa.

\footnotetext{
${ }^{2}$ Devido ao grande número de citações retiradas do primeiro tomo (de dois) das Obras completas de Jorge Luis Borges publicado pela Emecé em 1974 (cf. Bibliografia), a partir desse ponto do texto, todas as referências a esse livro serão feitas apenas utilizando a numeração da página.
} 
Apesar de terem o conhecimento da regência básica que arma a Biblioteca, seus habitantes, aparentemente, procuram outra coisa: a regra da disposição desses livros, a localização de si mesmos. O livro dos livros não é descrito como um texto detentor de verdades reveladoras; ele é um catálogo, um mapa, uma descrição precisa da própria biblioteca (e, nesse sentido, sua reprodução, seu ponto hermenêutico mais concreto - ainda que, como veremos, todos o sejam).

Vale notar que essa temática é semelhante àquela, clássica da modernidade weberiana, de que o homem não teria mais acesso a uma totalidade, de que lhe falta agora a compreensão dos mecanismos que regem a vida. Poderíamos então, dar outro passo, e realizar outro gesto já previsto dentro de certa tradição, comparando e reduzindo o texto de Borges aos de Kafka (com certa leitura de Kafka), em sua semelhança mais aparente com O Processo. ${ }^{3}$

Contudo, seria verdade que falta aos bibliotecários uma consciência da lei pela qual são regidos (e punidos, como muitos descrevem), pela qual a biblioteca é constituída? Ora, desde o início nos é oferecido o estatuto básico da biblioteca, sua equação mínima. Além disso, não há livro que suporte qualquer verdade que em outro livro não encontre sua negação, e ainda, um terceiro que ofereça a refutação da refutação. Não há catálogo total que não seja provisório, que não seja desmentido por outro. $\mathrm{O}$ sonho de um acesso total à Biblioteca não passa de uma ilusão provisória, algo que pode ser visto na contradição entre o que este trecho anuncia como "Tudo" (aquilo que se pode expressar, em todos os idiomas) e a impossibilidade de fixá-lo num ponto hermenêutico de certeza:

Todo: la historia minuciosa del porvenir, las autobiografías de los arcángeles, el catálogo fiel de la Biblioteca, miles y miles de catálogos falsos, la demostración de la falacia de esos catálogos, la demostración de la falacia del catálogo verdadero, el evangelio gnóstico de Basilides, el comentario de ese evangelio, el comentario del comentario de ese evangelio, la relación verídica de tu muerte, la versión de cada libro a todas las lenguas, las interpolaciones de cada libro en todos los libros, el tratado que Beda pudo escribir (y no escribió) sobre la mitología de los sajones, los libros perdidos de Tácito (BORGES, 1974, p. 467468).

Mais que isso: podemos dizer que essa expectativa de localizar a realização última de seu mecanismo - o catálogo dos catálogos - é a base fundante (e ausente) de seu poder. Da mesma forma, mesmo se K. tivesse ciência do conteúdo da lei que o julga, isso não o faria escapar da condenação. A causa de sua angústia não é a abstinência de um direito ou sua incompreensão. Assim como toda a fala é uma tautologia na Biblioteca, todo o direito ou toda a busca pelo direito é uma tautologia da Lei.

Os bibliotecários de Borges, no entanto, parecem se dirigir para esse caminho, para esse desejo perverso de ser uno com a lei, na Lei. Isso se observa, por um lado, na busca por um catálogo total; por outro, que é sua alternativa oposta e complementar, naquela "elegante esperança" que o narrador oferece ao fim do conto.

\footnotetext{
${ }^{3}$ Seria possível escrever uma história dessas comparações na recepção das obras de Borges, em especial, daquelas que a depreciam, considerando-a uma mera versão latino-americana de Kafka. Não se trata aqui, porém, de negar essa associação, mas de entendê-la do mesmo modo que Borges propôs em "Kafka y sus precursores", ensaio de Otras inquisiciones: a de que esse vínculo trabalha em mão dupla, iluminando tanto a obra do escritor mais contemporâneo como também aquela que o precede.
} 


\begin{abstract}
Acabo de escribir infinita. No he interpolado ese adjetivo por una costumbre retórica; digo que no es ilógico pensar que el mundo es infinito. Quienes lo juzgan limitado, postulan que en lugares remotos los corredores y escaleras y hexágonos pueden inconcebiblemente cesar -lo cual es absurdo-. Quienes lo imaginan sin límites, olvidan que los tiene el número posible de libros. Yo me atrevo a insinuar esta solución del antiguo problema: La Biblioteca es ilimitada y periódica. Si un eterno viajero la atravesara en cualquier dirección, comprobaría al cabo de los siglos que los mismos volúmenes se repiten en el mismo desorden (que, repetido, sería un orden: el Orden). Mi soledad se alegra con esa elegante esperanza. (BORGES, 1974, p. 471)
\end{abstract}

Da mesma forma que a busca por um catálogo capaz de fornecer uma consciência total da Biblioteca é motivada pelo anseio de ocupar o lugar da lei, cumprindo-a, a esperança de uma biblioteca de Bibliotecas é também um desejo pela iterabilidade ilimitada dessa ordem (a Ordem). Por isso, lendo mais de perto, perceberemos que não há "excedente" nessa biblioteca: todos os tomos são necessários (ainda que sejam passíveis de sacrifício, sejam dados à destruição) devido a sua totalidade hermenêutica, porque cada um reitera as coordenadas dessa estrutura infinita chamada Biblioteca: a de que todos os 25 símbolos gráficos foram utilizados até a exaustão. Cada livro da biblioteca já funciona como um catálogo total e cada biblioteca já é o catálogo de todas as bibliotecas. Por isso, não importam os conteúdos possíveis que um livro possível venha a exibir, pois o lugar que ocupa na estante, na economia geral da biblioteca, já sobrepõe qualquer enunciado como consumação de uma lei, como consumo das possibilidades disponíveis.

O que então significa o infinito aqui? Esse atributo da Biblioteca parece ser o mais caro para o narrador, pois, apesar das frequentes hesitações ao longo do texto - "El universo (que otros llaman la Biblioteca) se compone de un número indefinido, y talvez infinito" (BORGES, 1974, p.465, grifo meu) ou "la Biblioteca es total y que sus anaqueles registran todas las posibles combinaciones de los veintitantos símbolos ortográficos (número, aunque vastísimo, no infinito)" (BORGES, 1974, p.466, grifos meus), entre outras - o narrador toma como ponto de chegada de seu texto a demonstração triunfante de que a biblioteca é infinita. Que infinitude é essa que é a reincidência do mesmo?

\title{
$2 \mathrm{O}$ infinito e a eternidade como atributos do inferno
}

O tema do infinito enquanto propriedade diabólica é frequente na obra de Borges: o terrível daquilo que se perpetua indefinidamente ("Entonces Bioy Casares recordó que uno de los heresiarcas de Uqbar había declarado que los espejos y la cópula son abominables, porque multiplican el número de los hombres" (BORGES, 1974, p. 431)), em "Tlön, Uqbar, Orbis Tertius"; de uma memória prodigiosa que resvala no tédio e na imobilidade ("Funes el memorioso"); de uma arbitrariedade tão grande e tão múltipla que, ao querer figurar como um ideário de liberdade e justiça, resulta num regime de opressão ("La lotería en Babilonia"); ou de uma maravilha que resume todos os pontos do universo num único 
ponto e cuja consequência mais imediata é uma produção poética medíocre ("El Aleph"). ${ }^{4}$ Todas essas máquinas - o Aleph, a loteria, a memória como mero acúmulo do que se passou, a enciclopédia, enfim, a Biblioteca - funcionam de maneira similar: são aparatos de somar, capazes de produzir o infinito e a eternidade, de forma calculada. Aqui, estamos muito próximos daquilo que Hegel (1968) chamava o "mal-infinito" e, Derrida (2004), o “infinito calculável”. Como já foi dito, cada livro já é o símbolo de toda a biblioteca, porque é apenas a partir da soma de cada um deles (e em cada um deles) que ela encerra a dinâmica de sua clausura. Mesmo a possibilidade dos volumes serem destruídos, possibilidade que não afeta em nada a Biblioteca como um todo ("la Biblioteca es tan enorme que toda reducción de origen humano resulta infinitesimal”, (BORGES, 1974, p.469), é também uma propriedade que apenas exibe o poder que há no processo de cálculo. A operação é infinita,ainda que sua realização se dê por uma somatória tediosa de cada um dos elementos individuais - e é exatamente isso que polpa a máquina, que a faz funcionar indefinidamente.

Da mesma forma, utilizando um vocabulário distinto, poderíamos dizer que essa é uma biblioteca "policial", no sentido traçado por Rancière (1996): um espaço que, em sua divisão espacial, já preordena as possibilidades daquilo que pode surgir ou atuar - aquilo que ao oferecer lugar para o que é possível, faz a manutenção da própria ordem: "Lo repito: basta que un libro sea posible para que exista. Sólo esta excluido lo imposible" (BORGES, 1974, p. 469). A infinitude da Biblioteca presume sua (má) eternidade. Eis os dois corolários que as gerações de bibliotecários deduziram a partir de séculos vivendo no seu interior:

El primero: La Biblioteca existe ab aeterno. De esa verdad cuyo corolario inmediato es la eternidad futura del mundo, ninguna mente razonable puede dudar [...] El segundo: El número de símbolos ortográficos es veinticinco. Esa comprobación permitió, hace trescientos años, formular una teoría general de la Biblioteca y resolver satisfactoriamente el problema que ninguna conjetura había descifrado: la naturaleza informe y caótica de casi todos los libros (BORGES, 1974, p. 466, grifos do autor).

Dessas duas deduções apresentadas como séries descritivas distintas, o narrador derivará uma única regra: "La biblioteca es infinita y periódica" (BORGES, 1974, p. 471, grifos no original). Ao fazer essa unificação, percebe-se que, na verdade, os axiomas anteriores estão intimamente imbricados, constituem um ao outro, reafirmando-se num fracasso dialético que produz a ordem desse universo. Podemos inclusive definir sua

\footnotetext{
${ }^{4}$ Há uma leitura recorrente, e bastante embasada, de que esse conto seria uma espécie de sátira a Pablo Neruda (cf., por exemplo, Bloom, 1995). Essa leitura me parece produtiva, se pensarmos nos constantes ataques de Borges a estilística e ao conceito de "enumeração caótica" cunhado por Leo Spitzer (1945), texto em que o exemplo latino-americano oferecido é justamente Neruda. Tais ataques são encontrados por toda a obra de Borges, especialmente quando descreve sua relação ambígua com a poesia de Walt Whitman (tido como modelo primeiro da enumeração caótica para Spitzer), a quem admira profundamente, ainda que frequentemente aponte que "sus deliberadas enumeraciones no siempre pasan de catálogos insensibles" (p.1081), como acontece no prólogo a El oro de los tigres. A crítica a uma estrutura poética que consiste na tentativa do esgotamento pela enumeração de certos elementos cuja ordem não estaria enunciada ou disponível certamente tem parentescos com o problema discutido aqui, a partir do conto "La biblioteca de Babel". No entanto, seria necessário desdobrar essa questão em pelo menos dois pontos: 1) como Borges retoma esse problema em sua poesia e em sua poética; 2) como tal oposição a Neruda encontra ecos na produção contemporânea, isto é, como a oposição que Borges faz a tal estratégia ganha novas proporções dentro da literatura latino-americana atual. O exemplo mais evidente aqui é justamente Roberto Bolaño (2006), que em "Carnet de Baile" enumera (não por acaso...) os motivos pelos quais não se deve tirar Pablo Neruda para dançar.
} 
estrutura como uma eternidade espacializada, que dispondo todas as possibilidades conferidas dentro da linearidade temporal que constitui os textos em um único momento, que é um presente infinitamente repetido, neutraliza tanto as relações humanas como os vínculos com o tempo, com a linguagem, com a escritura, por oferecê-las de antemão. Não à toa, não só na definição do narrador desse conto ("Que el cielo exista, aunque mi lugar sea el infierno" (BORGES, 1974, p. 470). Esse céu não é outra coisa que o "livro total", ou seja, o paraíso aqui só é imaginável no inferno das estantes da Biblioteca), como na de Borges em vários de seus ensaios, certa noção de eternidade é intercambiável com a de inferno. Ao refletir sobre esse lugar de punição (e a natureza dessa punição), sobre "el espanto admirable de su invención", dirá em "La duración del infierno", do volume Discusión, que "El atributo de eternidad es el horroroso" (BORGES, 1974, p. 236). Ele será tão insuportável que o escritor argentino não só dedicará um texto para refutar o conceito de eterno retorno de Nietzsche ("La doctrina de los ciclos"), como também o livro inteiro (Historia de la eternidad) para denunciar as limitações dessa ideia em diversas filosofias, religiões e culturas, como que tentando destituir a legitimidade de conceitos programáticos de infinito, reservando-o para aquilo que é da ordem da indeterminação ou do impensável.

Como se não bastassem essas evidências, é possível regressar ainda mais na genealogia textual desse conto, mostrando que esse procedimento de denúncia de uma infinitude diabólica está como que em sua base fundacional, por assim dizer. Isso se torna explícito em um ensaio intitulado "La biblioteca total", publicado na revista Sur no59 (1939), não recolhido em nenhum dos livros organizados pelo autor, e que, em vários pontos, serve como uma primeira versão de "La biblioteca de Babel", da qual, inclusive, parágrafos inteiros serão recuperados praticamente sem modificações. Além de elencar os precursores dessa noção de biblioteca total - Leucipo, Demócrito de Abdera, os estoicos, Nietzsche (com a ideia do eterno retorno), Lewis Carroll, Aldous Huxley, Gustav Theodor Fechner e Kurd Lasswitz -, Borges (1999) define-os como detentores da invenção e da propagação de um mecanismo diabólico. Concluí o texto da seguinte forma:

\begin{abstract}
Uno de los hábitos de la mente es la invención de imaginaciones horribles. Ha inventado el Infierno, ha inventado la predestinación al Infierno, ha imaginado las ideas platónicas, la quimera, la esfinge, los anormales números transfinitos (donde la parte no es menos copiosa que el todo), las máscaras, los espejos, las óperas, la teratológica Trinidad: el Padre, el Hijo y el Espectro insoluble, articulados en un solo organismo... Yo he procurado rescatar del olvido un horror subalterno: la vasta Biblioteca contradictoria, cuyos desiertos verticales de libros corren el incesante albur de cambiarse en otros y que todo afirman, lo niegan y lo confunden como una divinidad que delira. (BORGES, 1999, p. 27)
\end{abstract}

Por isso, enfim, podemos chamar a Biblioteca de Babel, com justiça a obra de Borges, de uma biblioteca infernal.

\title{
3 Arquivos-mortos como formas de vida
}

Poderíamos então ousar perguntar, onde se localiza o livro de Borges nessa Biblioteca, nas nossas bibliotecas? O escritor não era indiferente a esse problema, pois já adianta em seu título, já sabe que, num certo sentido, sua obra também é um fac-símile, uma tautologia que merece o nome de Ficciones. Esse nome, que também indica um endereço (e um endereçamento), é o componente que se sobrepõe para Borges, para o problema que sua obra enfrenta, naqueles códigos com que se assinam as lombadas dos livros (aquilo que o bibliotecário-narrador designa como a raiz de sua descoberta, sua 
revelação), símbolo da Ordem das arquibibliotecas, o CDD (Classificação Decimal Dewey) designada por quatro números (863.4) - que codifica e pré-determina o espaço das "Ficções argentinas do século XX." E Borges (1974) sabe que esse elemento, essa posição define algo que excede as possibilidades "internas" que as bibliotecas reservam ao seu texto, que não é possível reverte-lo pela força de sua escrita (e sabemos como Borges tentou pervertê-los com inúmeras formas), nem na de nenhum outro autor. Essa biblioteca infernal tem já em sua estrutura o lugar prévio para as ficções, já na promessa de seu esgotamento, de sua exaustão. Por isso, é essa forma mesma de organização concreta e simbólica que deve ser posta em jogo.

Não há dúvida que esse dispositivo da biblioteca infernal seja um caso exemplar da "impressão" que Jacques Derrida (2001) chama de mal de arquivo. Um caso que se localiza justamente naquele nó entre o impulso de preservação e o de destruição do arquivo, da preservação da destruição e pela destruição. Entre a necessidade do registro, de salvaguardar a memória, opera-se uma redução inevitável, própria ao arquivo, dentro da qual certa força escritural tenta instaurar contradições, conflitos, que, no entanto, não raras vezes, recebe como resposta, e com efeitos de anulação, a proliferação dos espaços de compartimento - operação de destruição pela conservação, em nome dela. Isso fica claro, mais especificamente, quando Derrida (2001) descreve a aparição do princípio divino (o depositário de uma força totalizante, inclusive arquívica) como necessariamente acompanhado de um demônio que parece desafiá-lo em sua exterioridade (exterioridade conferida pelo poder divino) e que acaba atuando como uma existência que não age se não para justificar esse primeiro poder, desculpá-lo:

Dito de outra maneira, a destruição radical pode ainda ser reinvestida numa outra lógica, no inesgotável recurso economístico de um arquivo que capitaliza tudo, incluindo aquilo que o arruína ou contesta radicalmente seu poder: o mal radical pode ainda servir, a infinita destruição pode ser reinvestida numa teodiceia, o Diabo pode também justificar[...] (DERRIDA, 2001, p.24)

Na economia de nossas bibliotecas, a preservação total dos arquivos, incluindo dos arquivos futuros (que já estão no passado; as Vindicações já estão escritas, as verdadeiras e as falsas) já está garantida, arruinando-os. Da mesma forma, a promessa de uma exterioridade faz parte da própria estrutura de poder que ela detém sobre aqueles que nela vivem. Deus e o diabo se fundem na figura do catálogo geral, na biblioteca de bibliotecas.

Apesar disso, considero pouco produtivo encarar o problema da Biblioteca de Babel como o de um arquivo-morto que deve ser evitado a todo custo, um arquivo ao qual se oporia uma ideia de memória viva. Como o texto de Derrida (2001) não deixa de lembrar, tais arquivos, mesmo em sua abstinência, são bastante atuantes, inclusive, são promovedores de uma certa "vida".

E não é esse exatamente o problema de Adorno e Horkheimer (2006) na Dialética do Esclarecimento? Saber qual o tipo de "vida" que se produz dentro de em um regime de calculabilidade e de domínio da natureza? Borges reintroduz esse problema através de artefatos iluministas por definição - a enciclopédia e a biblioteca moderna - questionando a constituição de nossas formas de vida que se deram também por esses modelos, e suas reverberações para a constituição e circulação da literatura, para as formas de relação com o texto literário e para a linguagem no geral. A noção iluminista de que o sujeito não participa da constituição do saber, mas apenas o extraí da natureza, já indica uma antecedência metafísica que acaba derivando incessantemente em repetição. $\mathrm{O}$ narrador de "La biblioteca de Babel" demonstra sua crença e seu temor nessa perspectiva no próprio ato de escrever sua história: "La escritura metódica me distrae de la presente condición de 
los hombres. La certidumbre de que todo está escrito nos anula o nos afantasma" (BORGES, 1974, p. 470). É essa fantasmagoria do sujeito que Adorno e Horkheimer (2006, p. 23-24) descrevem como o desenrolar dessa noção de conhecimento:

\begin{abstract}
O princípio da imanência, a explicação de todo acontecimento como repetição, que o esclarecimento defende contra a imaginação mítica, é o princípio do próprio mito. A insossa sabedoria para a qual não há nada de novo sob o sol, porque todas as cartas do jogo sem-sentido já teriam sido jogadas, porque todos os grandes pensamentos já teriam sido pensados, porque as descobertas possíveis poderiam ser projetadas de antemão, e os homens estariam forçados a assegurar a autoconservação pela adaptação - essa insossa sabedoria reproduz tão-somente a sabedoria fantástica que ela rejeita: a ratificação do destino que, pela retribuição, reproduz sem cessa o que já era. O que seria diferente é igualado. Esse é o veredicto que estabelece criticamente os limites da experiência possível. O preço que se paga pela identidade de tudo com tudo é o fato de que nada, ao mesmo tempo, pode ser idêntico consigo mesmo.
\end{abstract}

Podemos encarar os arquivos das ditaduras militares latino-americanas dentro desse mesmo leque de problemas: não como arquivos cuja ameaça é a de se tornarem mortos, nem como arquivo dos mortos, mas como arquivos que determinam a vida (incluindo a vida dos mortos, e a morte dos vivos).

E dentro dessa questão que as literaturas das últimas décadas se mobilizaram, buscando revisar e refutar certas estratégias discursivas para lidar com esses arquivos, com a posição da literatura em relação a essa massa de papéis espoliados, e mesmo repensando se seu lugar discursivo e suas condições enunciativas oferecem possibilidades de se fazer justiça à memória desse período. Aqui, as consequências do mecanismo formalizado por Borges ficam mais evidentes: a tensão que toda biblioteca possui por ser também um arquivo.

A Biblioteca (assim como os regimes ditatoriais) suporta mal os mortos. Não há cadáveres nela: "Muerto, no faltarán manos piadosas que me tiren por la baranda; mi sepultura será el aire insondable: mi cuerpo se hundirá largamente y se corromperá y disolverá en el viento engendrado por la caída, que es infinita” (BORGES, 1974, p. 38). Mas certamente há lugares para os mais determinados gêneros bio-gráficos (autobiográfico, histórico, enciclopédico, ficcional), todos devidamente previstos em nossa biblioteca infernal. Nela, a voz viva dos mortos desempenha o seu papel na escrita morta dos vivos. ${ }^{5}$

É esse problema, esse duplo problema (que é também o da Biblioteca de Babel e o do lugar de Borges nela, as ficciones que lhe foram reservadas) é que certa literatura latinoamericana contemporânea tenta enfrentar. Na passagem da ditadura para a democracia, da invisibilidade dos arquivos para sua visibilidade, da volta dos mortos para seu enterro, resta a dúvida de se a biblioteca não é a mesma, se a outra biblioteca que se mostra agora não é a outra "que repete a mesma desordem" e que reitera a Ordem. Desse modo a

\footnotetext{
5 Dentro da produção mais recente, esse tópico foi retomado pelo poeta argentino Martín Gambarotta, em Punctum (2011), que reescreve o poema "Cadáveres" de Néstor Perlongher, cujo estribilho é "Hay cadáveres", respondendo-lhe: "No hay, no va a haber, no hubo/ no hubo, no, no hay no va a haber/ ni hubiese habido si; no hubo,/ [...] No va a haber, Cadáver, mañanas/ reales de color tierra/ para usar el gatillo, un gatillo difícil,/ tenso, que se resiste a ser gatillado/ contra algún objetivo enemigo, [...]" (GAMBAROTTA, 2011, p. 26-27). O problema passa da denuncia da existência de execuções indistintamente realizadas, de cadáveres escondidos sob a terra, de registros perdidos na memória, para a impossibilidade mesma de recuperação desses corpos dentro de regime que está disposto a tudo registrar e expor em arquivos, de uma "democracia" que estabelece sua legitimidade como "não ditadura" e não como processo de enfrentamento dessa memória. Para uma interpretação um pouco distinta desses dois poemas, confira Kamenszain (2007).
} 
problemática enunciativa do texto literário se reduplica: não somente a tensão entre o que é anunciado e aquilo que é dito opera como conflito de forças escriturais, mas também a tensão daquilo que se escreve e desde onde se escreve (desde uma biblioteca simbólica que estabelece seu espaço enquanto "literatura") passa a ser objeto de tematizações e formalizações na literatura recente herdeira de Borges.

A visibilidade dos mortos e de outras formas de violência, sua exposição como forma de diferenciação de governabilidades - entre aqueles que escondem (as ditaduras) e os que os exibem (a democracia) - não deve ser entendida como uma espécie muito específica de dispositivo pan-óptico, próprio ao aparelho das bibliotecas infernais? Colocar "tudo" diante dos olhos, exaustivamente, pode ser também uma forma de manutenção da ordem.

Por isso é necessário se perguntar por uma outra economia da biblioteca. Não uma biblioteca que se organize para suportar o cadáver, mas que possa por a si mesma em questão para que projete um mero e genérico "futuro", mas sim outra forma de composição entre tempo, memória e escrita.

Dos atuais autores, parece-me que o chileno Roberto Bolaño (1953-2003) foi um dos escritores que souberam conjugar a biblioteca de Borges e as nossas atuais. Em La literatura nazi en América, ao descrever uma série de intelectuais que passivamente exibem máquinas de opressões - nazistas, ditatoriais, policiais e outras - reformulando-as esteticamente, em forma de literatura, Bolaño $(1996,2006)$ vê o risco de o cadáver, ou a memória que tenta fazer justiça a esse cadáver, ser arquivado na biblioteca infernal de Borges, na seção de "ficções" (apesar de não fazer diferença se a seção fosse outra - o mecanismo biblioteconômico neutralizador é que deve ser posto em questão aqui, não suas categorias). Vê, inclusive, o risco dos seus próprios livros já terem lugar na biblioteca dos ditadores. A distância que Bolaño $(1996,2006)$ tenta tomar desses dois - do ditador e do escritor, do ditador-escritor, já que eles parecem agora estar em aliança - parece exibir a própria dificuldade de se re-instaurar a força escritural diante de um arquivo, cinicamente aclamado como "público", operando a destruição da memória pela sua preservação.

Igualmente sensível ao assunto, o guatemalteco Rodrigo Rey Rosa, em El material humano (2009), expõe a disparidade entre as informações oferecidas pelas fichas de presos políticos encontras por seu narrador numa antiga delegacia e a superabundância de informações disponíveis sobre a vida cotidiana de Jorge Luis Borges nas mais de 1.600 páginas da edição dos diários de Adolfo Bioy Casares (2006), realizada por Daniel Martino. Nesse entrecruzamento, entre a atomização arquívica da violência autoritária e a hiperfetichização da biografia literária, se coloca a própria dignidade ética envolvida na possibilidade do narrador - que também leva o nome de seu autor - contar a sua história das forças de opressão de seu país e também de suas leituras pessoais (o Borges de Casares) a partir de sua perspectiva e por meio da escrita literária.

Seguindo o exemplo desses escritores, não deveríamos ler, pelo prisma que Borges propõe em seu texto, as recentes ações dos governos brasileiro - nas diversas negociações que desarticulam a Comissão de Verdade, sem deixar de instaurá-la - e chileno - com a nomeação eufemística da violência do período ditatorial na documentação oficial (histórica, jurídica e pedagógica)?

Não seria esse o risco e o prejuízo que palavras como "democracia" e "literatura" possuem hoje? 


\section{REFERÊNCIAS}

ADORNO, T. W.; HORKHEIMER, M. Dialética do esclarecimento: fragmentos filosóficos. Rio de Janeiro: Zahar, 2006.

AGUALUSA, J. E. Manual prático de levitação. Rio de Janeiro: Gryphus, 2005.

BLOOM, H. O cânone ocidental. Rio de Janeiro: Objetiva, 1995.

BOLAÑO, R. Carnet de Baile. In: Putas asesinas. Barcelona: Anagrama, 2006.

BOLAÑO, R. La literatura nazi en América. Barcelona: Seix Barral, 1996.

BORGES, J. L. Borges en Sur: 1931-1980. Buenos Aires: Emecé, 1991.

BORGES, J. L. Obra completa. Buenos Aires: Emecé, 1974. v. 1.

CASARES, A. B. Borges. Buenos Aires: Destino, 2006.

DERRIDA, J. Mal de arquivo: uma impressão freudiana. Rio de Janeiro: Relume-Dumará, 2001.

DERRIDA, J.; ROUDINESCO, E. De que amanhã... Rio de Janeiro: Jorge Zahar, 2004.

GAMBAROTTA, M. Punctum. Buenos Aires: Mansalva; Voz, 2011.

HEGEL, G. W. F. Ciencia de la lógica. Buenos Aires: Editora Solar; Hachette, 1968.

KAMENSZAIN, T. La boca del testimonio: lo que dice la poesía. Buenos Aires: Norma, 2007.

MICELI, S. Jorge Luis Borges: história social de um escritor nato. Novos Estudos Ceprab, São Paulo, v. 77, p. 155-182, mar. 2007.

RANCIÈRE, J. O desentendimento. São Paulo: Editora 34, 1996.

ROSA, R. R. El material humano. Barcelona: Anagrama, 2009.

SPITZER, L. La enumeración caótica en la poesía moderna. Buenos Aires: Universidad de Buenos Aires, 1945. 